\title{
The Solubility of Hydrocarbon Gases in Glassy Polymers: Fractal Modeling
}

\author{
Georgii V. Kozlov, ${ }^{1}$ Jorge A. Cruz-Morales, ${ }^{2}$ Joel Vargas, ${ }^{2}$ and Mikhail A. Tlenkopatchev ${ }^{2}$ \\ ${ }^{1}$ Kabardino-Balkarian State University, Chernishevsky Street 173, Nalchik 360004, Russia \\ ${ }^{2}$ Instituto de Investigaciones en Materiales, Universidad Nacional Autónoma de México, Apartado Postal 70-360, CU, Coyoacán, \\ 04510 México, DF, Mexico
}

Correspondence should be addressed to Mikhail A. Tlenkopatchev; tma@unam.mx

Received 26 April 2013; Revised 11 August 2013; Accepted 12 August 2013

Academic Editor: Ling-Shu Wan

Copyright (C) 2013 Georgii V. Kozlov et al. This is an open access article distributed under the Creative Commons Attribution License, which permits unrestricted use, distribution, and reproduction in any medium, provided the original work is properly cited.

\begin{abstract}
This work describes the fractal modeling of the solubility of $n$-alkanes, $n$-alkenes, methylacetylene, allene, ethylacetylene, and butadiene hydrocarbon gases in glassy poly(vinyltrimethylsilane) (PVTMS). The proposed equation represents satisfactorily the solubility coefficients of the hydrocarbon gases in glassy PVTMS as a function of the fractal dimension of the polymer and the effective diameter of a gas penetrant molecule. It is found that the calculated solubility coefficients have a good correlation with the experimental data. The proposed model can predict the solubility of hydrocarbon gases in glassy polymers.
\end{abstract}

\section{Introduction}

The separation of oxygen and nitrogen from air for the industrial combustion is carried out using membranes technology [1]. This technology is also used for the removal of hydrogen from mixtures with nitrogen or hydrocarbons in petrochemical processes [1]. Frozenness of polymer chains in the glassy state hinders chains fluctuations that give rise to the formation of channels through which the diffusant can migrate to a neighbor cavity. Here both solubility and diffusion may control gas separation of similar size; however, when the size of the diffusants largely differs, diffusion may be the controlling step. Furthermore glassy polymers with bulky side groups in their structure contain anomalous large cavities; such fact facilitates the gas permeability without adversely affecting the permselectivity. These polymers have in general high glass transition temperatures, and therefore aging processes that might affect the gas transport are not important at the temperatures of work. Polycarbonates, polysulfones, polyimides, and substituted polynorbornenes have attracted much attention for the gas separation [1-6].

It is important to devise methods that permit the prediction of the membrane performance for the gas separation as a function of the chemical structure. In this sense, the fractal modeling is an important tool for this purpose. Recently, authors proposed the fractal analysis of the gas permeability in semicrystalline polyethylene $[7,8]$.

Membranes prepared from PVTMS were industrially produced and used in the former Soviet Union and France. Furthermore, this material is known for more than 40 years as a polymer that exhibits a good $\mathrm{O}_{2}$ permeability and $\mathrm{O}_{2} / \mathrm{N}_{2}$ selectivity. In this regard, the aim of this study consists in applying fractal analysis to describe the solubility coefficients of the hydrocarbon gases in glassy PVTMS membranes.

\section{Materials and Methods}

In the framework of the fractal model, it is assumed that the solubility of simple gases which are not interacting with polymers proceeds by deposition of gas penetrant molecules on the walls of free volume microvoids (true sorption) [12]. In this case, the general solubility model of a gas in a polymer can be written as $[7,13]$

$$
S \sim F_{g}{ }^{D_{f} / 2},
$$

where $F_{g}$ is the cross-sectional area for the gas penetrant molecules and $D_{f}$ is the dimension of extra energy localization domains for the polymer structure $\left(D_{f}\right.$ is related to the 
fractal dimension of the polymer layer) [13]. The value of $D_{f}$ can be calculated in the following way.

The relative fraction of the closely packed segments in clusters $\left(\varphi_{\mathrm{cl}}\right)$ is a parameter of order in strict physical sense, and it is related to the glass transition temperature of the polymer $\left(T_{g}\right)$ through the following percolation correlation $[14,15]$ :

$$
\varphi_{\mathrm{cl}}=0.03\left(T_{g}-T\right)^{0.55},
$$

where $T$ is the temperature at which the parameter is measured $(T=293 \mathrm{~K})$.

The fractal dimension of the polymer structure $d_{f}$ can be calculated using [15]

$$
d_{f}=3-6\left(\frac{\varphi_{\mathrm{cl}}}{\mathrm{Cs} \cdot S_{\mathrm{cr}}}\right)^{1 / 2},
$$

where $d_{f}$ is the fractal dimension of the supermolecular (supersegmental) structure of the polymer, $S_{\text {cr }}$ is the crosssectional area of a macromolecule in $\AA^{2}$, and $C s$ is a characteristic ratio which is the index of chain flexibility $[16,17]$. The values of $C s$ and $S_{\text {cr }}$ can be estimated according to the literature $[13,17,18]$. Finally, the dimension of $D_{f}$ can be estimated from [19]

$$
D_{f}=1+\frac{1}{\left(3-d_{f}\right)} .
$$
4.33.

The calculated value of $D_{f}$ for the glassy PVTMS is $D_{f}=$

For the PVTMS, we have $T_{g}=440 \mathrm{~K}, T=293 \mathrm{~K}, \varphi_{\mathrm{cl}}=$ $0.467, d_{f}=2.70, \mathrm{Cs}=6.7$, and $S_{\mathrm{cr}}=22.7$.

In order to construct an effective model for the solubility coefficient (related to the permeability model of gas transport in polymer membranes $[4,13]$ ), we include the Lennard-Jones characteristic constant force potential $(\varepsilon / k)$ which describes the interactions between gas-gas molecules as a function of the distance [11]. Thus, the fractal model of the solubility coefficient can be written as

$$
S=S_{0}\left(F_{g}^{\mathrm{ef}}\right)^{D_{f} / 2}\left(\frac{\varepsilon}{k}\right)
$$

where $S$ is the solubility coefficient of a gas in the polymer $\left(\mathrm{cm}^{3}\right.$ of gas (STP) $/ \mathrm{cm}^{3}$ of polymer $\left.\mathrm{cmHg}\right), S_{0}$ is a constant, and $\left(F_{g}^{\mathrm{ef}}\right)$ is the effective square of a cross sectional-area of a gas penetrant molecule. It is worth noting that the values of the solubility coefficients of the hydrocarbon gases are not described by (5) using the known values of maximum $\left(d_{\max }\right)$ and minimum $\left(d_{\min }\right)$ gas diameters $[9,10]$. Here we have estimated for the $\mathrm{C}_{1}-\mathrm{C}_{4}$ hydrocarbon gases the effective diameter values $\left(d_{\mathrm{ef}}\right)$ taking into account the orientation of a gas molecule inside the microvoids in the polymer. The backcalculation of the effective diameter using the values of gas solubility shows the systematic increase of $d_{\mathrm{ef}} / d_{\text {min }}$ ratio as the Lennard-Jones characteristic constant force potential $(\varepsilon / k)$ increases (Figure 1). This correlation can be expressed by

$$
\frac{d_{\mathrm{ef}}}{d_{\mathrm{min}}}=1+1.15 \times 10^{-3}\left(\frac{\varepsilon}{k}\right) .
$$

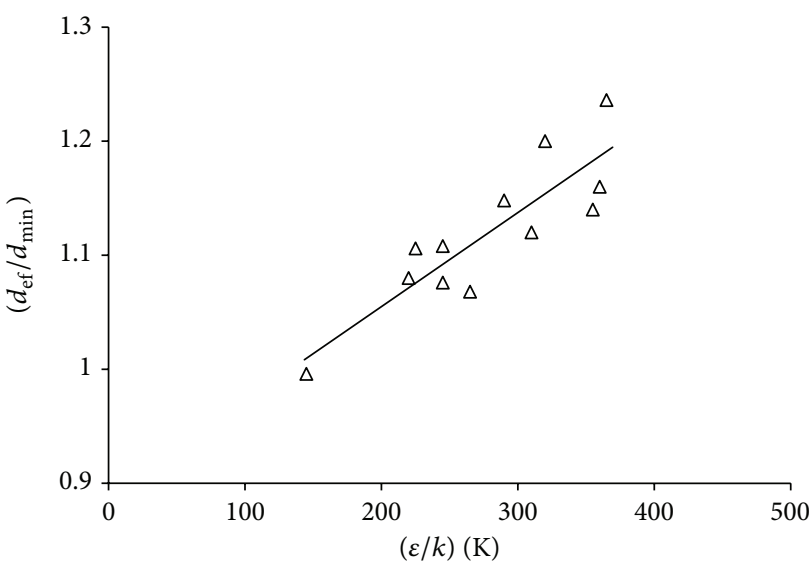

FIGURE 1: Plot of effective diameter and minimum diameter ratio $\left(d_{\mathrm{ef}} / d_{\text {min }}\right)$ of $\mathrm{C}_{1}-\mathrm{C}_{4}$ hydrocarbon gases against the Lennard-Jones characteristic constant force potential $(\varepsilon / k)$.

The values of $\left(F_{g}^{\mathrm{ef}}\right)$ in (5) are estimated from the effective diameter values $\left(d_{\mathrm{ef}}\right)$ of gas penetrant molecules calculated using (6).

\section{Results and Discussion}

The glassy membranes contain microvoids, which account for the excess volume in the glassy state. The presence of microvoids in glassy polymers is confirmed by numerous experiments $[20,21]$. The diameters of these microvoids have the value of several Angstroms and their walls are represented as vibrating centers around equilibrium positions of chain fragments. In other words, microvoids are a consequence of a critical displacement of kinetic units from an equilibrium position [22]. According to this model, solubility of a gas occurs in the continuous phase, whereas the microvoids act as sites where the gas is adsorbed. Successful gas adsorption requires not only an appropriate orientation of the molecules in microvoids but also the radius of the channel to be larger than the radii of the gas penetrant molecules.

The values of the effective diameter and minimum diameter ratio $d_{\mathrm{ef}} / d_{\min }$ of a gas penetrant against the Lennard-Jones characteristic constant force potential $(\varepsilon / k)(6)$ are shown in Figure 1 . It is seen that the values of $\left(d_{\mathrm{ef}} / d_{\text {min }}\right)$ ratio increase as the Lennard-Jones characteristic constant force potential $(\varepsilon / k)$ increases. This phenomenon can be explained by the orientation of gas penetrants during the sorption process. The orientation of a gas molecule inside the polymer means the increase of the effective diameter of a gas penetrant molecule. Consequently, the gas solubility coefficient increases as the effective diameter increases according to (5). The physical meaning of a constant $S_{0}$ in (5) can be determined from the following condition:

$$
\left(F_{g}^{\mathrm{ef}}\right)^{D_{f} / 2}\left(\frac{\varepsilon}{k}\right)=1 .
$$

Here we discuss the conditions for the realization of (7). The value of minimum diameter for the gas He is $1.8 \AA$, which 
TABLE 1: Values of diameters and force constants $(\varepsilon / k)$ of $\mathrm{C}_{1}-\mathrm{C}_{4}$ hydrocarbon gases for the calculation of a solubility coefficient in PVTMS.

\begin{tabular}{|c|c|c|c|c|}
\hline Hydrocarbon & $d, \AA[9,10]$ & $d_{\mathrm{ef}}, \AA[11]$ & $d_{\mathrm{ef}}, \AA$, from $(6)$ & $(\varepsilon / k), \mathrm{K}[11]$ \\
\hline $\mathrm{CH}_{4}$ & $3.3-4.2$ & $3.18 \pm 0.14$ & 3.30 & $154 \pm 15.6$ \\
\hline $\mathrm{C}_{2} \mathrm{H}_{6}$ & $3.7-5.2$ & $3.69 \pm 0.08$ & 4.06 & $250 \pm 22$ \\
\hline $\mathrm{C}_{3} \mathrm{H}_{8}$ & $4.1-5.8$ & $4.09 \pm 0.08$ & 4.76 & $305 \pm 28$ \\
\hline $\mathrm{C}_{4} \mathrm{H}_{10}$ & $4.6-6.9$ & $4.40 \pm 0.08$ & 5.66 & $364 \pm 35$ \\
\hline $\mathrm{C}_{2} \mathrm{H}_{4}$ & $3.6-5.5$ & $3.57 \pm 0.08$ & 3.82 & $225 \pm 15$ \\
\hline $\mathrm{C}_{3} \mathrm{H}_{6}$ & $4.1-5.4$ & $3.86 \pm 0.13$ & 4.63 & $294 \pm 32$ \\
\hline $\mathrm{C}_{4} \mathrm{H}_{8}$ & $4.5-5.2$ & 4.18 & 5.36 & 356 \\
\hline $\mathrm{C}_{2} \mathrm{H}_{2}$ & $3.5-5.7$ & $3.38 \pm 0.06$ & 3.70 & $223 \pm 23$ \\
\hline $\mathrm{C}_{3} \mathrm{H}_{4}(\mathrm{~m})^{\mathrm{a}}$ & $4.0-4.8$ & $3.62 \pm 0.07$ & 4.62 & $321 \pm 25$ \\
\hline $\mathrm{C}_{4} \mathrm{H}_{6}(\mathrm{e})^{\mathrm{b}}$ & $4.4-5.0$ & 3.81 & 5.26 & 360 \\
\hline $\mathrm{C}_{3} \mathrm{H}_{4}(\mathrm{a})^{\mathrm{c}}$ & $4.6-4.9$ & $3.64 \pm 0.07$ & 5.38 & $335 \pm 14$ \\
\hline $\mathrm{C}_{4} \mathrm{H}_{6}(\mathrm{~b})^{\mathrm{d}}$ & 5.0 & 3.85 & 5.45 & 327 \\
\hline
\end{tabular}

${ }^{\mathrm{a}} \mathrm{m}$ is methylacetylene.

${ }^{b}$ is ethylacetylene.

$c a$ is allene.

${ }^{\mathrm{d}} \mathrm{b}$ is butadiene.

TABLE 2: Comparison of calculated $\left(S_{\text {cal }}\right)$ and experimental $\left(S_{\exp }\right)$ values of solubility coefficient of hydrocarbon gases in PVTMS.

\begin{tabular}{lccc}
\hline Hydrocarbon & $d_{\mathrm{ef}}, \AA$, from $(6)$ & $S_{\text {exp }} \times 10^{-3^{\mathrm{a}}[11]}$ & $S_{\text {cal }} \times 10^{-3^{\mathrm{a}}}$, from $(6)$ \\
\hline $\mathrm{CH}_{4}$ & 3.30 & 10 & 15 \\
$\mathrm{C}_{2} \mathrm{H}_{6}$ & 4.06 & 70 & 109 \\
$\mathrm{C}_{3} \mathrm{H}_{8}$ & 4.76 & 400 & 421 \\
$\mathrm{C}_{4} \mathrm{H}_{10}$ & 5.66 & 1660 & 1766 \\
$\mathrm{C}_{2} \mathrm{H}_{4}$ & 3.82 & 47 & 63 \\
$\mathrm{C}_{3} \mathrm{H}_{6}$ & 4.63 & 310 & 332 \\
$\mathrm{C}_{4} \mathrm{H}_{8}$ & 5.36 & - & 1163 \\
$\mathrm{C}_{2} \mathrm{H}_{2}$ & 3.70 & 33 & 49 \\
$\mathrm{C}_{3} \mathrm{H}_{4}(\mathrm{~m})^{\mathrm{b}}$ & 4.62 & 300 & 357 \\
$\mathrm{C}_{4} \mathrm{H}_{6}(\mathrm{e})^{\mathrm{c}}$ & 5.26 & - & 1022 \\
$\mathrm{C}_{3} \mathrm{H}_{4}(\mathrm{a})^{\mathrm{d}}$ & 5.38 & 315 & 403 \\
$\mathrm{C}_{4} \mathrm{H}_{6}(\mathrm{~b})^{\mathrm{e}}$ & 5.45 & - & 981 \\
\hline
\end{tabular}

${ }^{\mathrm{a}}$ Units of $S: \mathrm{cm}^{3}$ of gas (STP)/( $\mathrm{cm}^{3}$ of polymer $\left.\mathrm{cmHg}\right)$.

${ }^{\mathrm{b}} \mathrm{m}$ is methylacetylene.

${ }^{c} \mathrm{e}$ is ethylacetylene.

$\mathrm{d}_{\mathrm{a}}$ is allene.

${ }^{\mathrm{e}} \mathrm{b}$ is butane.

corresponds to $F_{g}^{\mathrm{ef}}=2.54 \AA$ [23]. The value of $D_{f}$ can be alternatively estimated using

$$
D_{f}=2 \frac{(1-v)}{(1-2 v)},
$$

where $v$ is Poisson's coefficient.

The minimum value of $v(v=-1)$ in (8) corresponds to $D_{f}=1.33$. In this case, the criterion for (7) has the condition $(\varepsilon / k)=0.583 \mathrm{~K}$. This value about 3 orders of magnitude is lower than the values of $\varepsilon / k$ for the hydrocarbons of $C_{1}-C_{4}$ [19]. This means that the value of $S_{0}$ in (5) corresponds to a minimum solubility of a gas molecule where a gas molecular interaction does not count. Thus, the estimated values of $S_{0}$ for PVTMS are equal to $4.0 \times 10^{-8}$. Table 1 shows the values of diameters and force constants $(\varepsilon / k)$ of $\mathrm{C}_{1}-\mathrm{C}_{4}$ hydrocarbons.
As shown in Table 1 , the $d_{\text {ef }}$ values of hydrocarbons, calculated by (6), are higher than the $d_{\text {min }}$ values according to $[9,10]$. The latter could be attributed to the orientation of the gas penetrant molecules during sorption inside the microvoids in the polymer.

Table 2 shows the experimental $S_{\exp }$ [11] and calculated $S_{\text {cal }}$ results of the solubility coefficients for the hydrocarbon gases in PVTMS. The results indicate that a good concordance between the calculated $S_{\text {cal }}$, using (5), and experimental $S_{\text {exp }}$ values of the solubility coefficient is observed. A reasonable agreement is also observed for the larger molecules of $\mathrm{C}_{4} \mathrm{H}_{6}$ and $\mathrm{C}_{4} \mathrm{H}_{8}$. The values of the solubility coefficient follow the trend $S\left(\mathrm{CH}_{4}\right)<S\left(\mathrm{C}_{2} \mathrm{H}_{2}\right)<S\left(\mathrm{C}_{2} \mathrm{H}_{4}\right)<S\left(\mathrm{C}_{3} \mathrm{H}_{4}\right)<$ $S\left(\mathrm{C}_{2} \mathrm{H}_{6}\right)<S\left(\mathrm{C}_{3} \mathrm{H}_{6}\right)<S\left(\mathrm{C}_{4} \mathrm{H}_{10}\right)$.

As a powerful tool, the fractal model can also be used to estimate other variables such as permeability and selectivity 
in gas transport through polymeric membranes. In this regard, we are trying to obtain the experimental parameters of the fractal model to achieve the theoretical values of the permeability and solubility coefficients in amorphous polymers such as polynorbornene dicarboximides with different pendant groups (phenyl, adamantyl, and cyclohexyl), reported in previous work [24].

\section{Conclusions}

Equation (5) represents satisfactorily the solubility coefficients for the $\mathrm{C}_{1}-\mathrm{C}_{4}$ hydrocarbon gases in a glassy PVTMS. According to this equation, the values of the solubility coefficient depend on the size of the gas penetrant molecules, their molecular interactions with the polymer, and fractal dimensions of the polymer. The solubility coefficients increase as the effective diameters of the gases also increase. In all cases, the calculated results are in good agreement with experimental data. The fractal modeling proposed in this study should be useful for the prediction of the gas solubility in glassy polymer membranes.

\section{Conflict of Interests}

The authors declare that there is no conflict of interests regarding the publication of this paper.

\section{Acknowledgments}

The authors thank CONACYT-SEMARNAT (Contract 23432) for generous support for this research.

\section{References}

[1] R. E. Kesting and A. K. Fritzche, Polymeric Gas Separation Membranes, chapter 6, John Wiley \& Sons, New York, NY, USA, 2nd edition, 1993.

[2] H. Ohya, V. V. Kudryavtsev, and S. I. Semenova, Polyimide Membranes: Applications, Fabrication and Properties, Kondansha, Tokyo, Japan, 1996.

[3] W. J. Koros and G. K. Fleming, "Membrane-based gas separation," Journal of Membrane Science, vol. 83, no. 1, pp. 1-80, 1993.

[4] D. R. Paul and Y. P. Yampolskii, Polymeric Gas Separation Membranes, chapter 4, CRC Press, Boca Raton, Fla, USA, 1994.

[5] A. Pineda Contreras, M. A. Tlenkopatchev, M. Del Mar LópezGonzález, and E. Riande, "Synthesis and gas transport properties of new high glass transition temperature ring-opened polynorbornenes," Macromolecules, vol. 35, no. 12, pp. 4677-4684, 2002.

[6] J. Vargas, A. A. Santiago, M. A. Tlenkopatchev, M. LópezGonzález, and E. Riande, "Gas transport in membranes based on polynorbornenes with fluorinated dicarboximide side moieties," Journal of Membrane Science, vol. 361, no. 1-2, pp. 78-88, 2010.

[7] G. V. Kozlov, V. V. Afaunov, N. I. Mashukov, and Y. S. Lipatov, Fractal and Local Order in Polymeric Materials, Nova Science, New York, NY, USA, 2001.

[8] G. V. Kozlov and G. E. Zaikov, "The diffusion of gases in semicrystalline polyethylene and its melt," Vysokomolekularnye
Soedineniya B, vol. 45, no. 7, pp. 1197-1201, 2003 (Russian), English translation Polymer Science Series B, vol. 45, pp. 181187, 2003.

[9] A. S. Michaels and H. J. Bixler, "Solubility of gases in polyethylene," Journal of Polymer Science, vol. 50, pp. 393-412, 1961.

[10] A. R. Berens and H. B. Hopfenberg, "Diffusion of organic vapors at low concentrations in glassy PVC, polystyrene, and PMMA," Journal of Membrane Science, vol. 10, no. 2-3, pp. 283-303, 1982.

[11] V. V. Teplyakov and S. G. Durgaryan, "On the relation between the parameters of permeability of gases and hydrocarbons in polymers," Vysokomolekulyarnye Soedineniya A, vol. 28, pp. 564-572, 1986 (Russian).

[12] E. Baer, Engineering Design For Plastic, chapter 2, Reinhold Publishing, New York, NY, USA, 1963, Khimiya, Moscow, Russia, 1967.

[13] G. V. Kozlov and G. E. Zaikov, Fractals Analysis of Gas Transport in Polymers, chapters 2, 3 and 5, Nova Science, New York, NY, USA, 2008.

[14] V. I. Novikov and G. V. Kozlov, "Fractal analysis of macromolecules," Uspekhi Khimii, vol. 69, pp. 378-397, 2000, English translation Russian Chemical Reviews, vol. 69, pp.347-366, 2000.

[15] G. V. Kozlov, L. K. Nafadzokova, and G. E. Zaikov, "Fractal model of the free volume of vitreous poly(vinyltrimethylsilane) from data on gas diffusion," Glass Physics and Chemistry, vol. 33, no. 5, pp. 481-485, 2007.

[16] V. P. Budtov, Physical Chemistry of Polymer Solutions, Khimiya, Saint-Petersburg, Russia, 1992, (Russian).

[17] S. M. Aharoni, "On entanglements of flexible and rodlike polymers," Macromolecules, vol. 16, no. 11, pp. 1722-1728, 1983.

[18] S. Wu, "Chain structure and entanglement," Journal of Polymer Science B, vol. 27, no. 4, pp. 723-741, 1989.

[19] A. S. Balankin, Synergetics of Deformed Solids, vol. 1, Publishing House of the Ministry of Defense of the USSR Press, Moscow, Russia, 1991, (Russian).

[20] B. D. Malhotra and R. A. Pethrick, "Positronium annihilation studies of polycarbonate, polyethersulphone and polysulphone," European Polymer Journal, vol. 19, no. 6, pp. 457-459, 1983.

[21] Q. Deng, F. Zandiehnadem, and Y. C. Jean, "Free-volume distributions of an epoxy polymer probed by positron annihilation: temperature dependence," Macromolecules, vol. 25, no. 3, pp. 1090-1095, 1992.

[22] D. S. Sanditov and G. V. Kozlov, "On the nature of fluctuation holes in a simplest model of relaxation in amorphous polymers," Vysokomolekulyarnye Soedineniya A, vol. 38, pp. 1389-1398, 1996 (Russian), English translation Polymer Science A, vol 38, pp. 919-923, 1996.

[23] N. I. Nikolaev, Diffusion in Membranes, Khimiya, Moscow, Russia, 1980, (Russian).

[24] M. A. Tlenkopatchev, J. Vargas, M. D. M. López-González, and E. Riande, "Gas transport in polymers prepared via metathesis copolymerization of exo-N-phenyl-7-oxanorbornene-5,6dicarboximide and norbornene," Macromolecules, vol. 36, no. 22, pp. 8483-8488, 2003. 

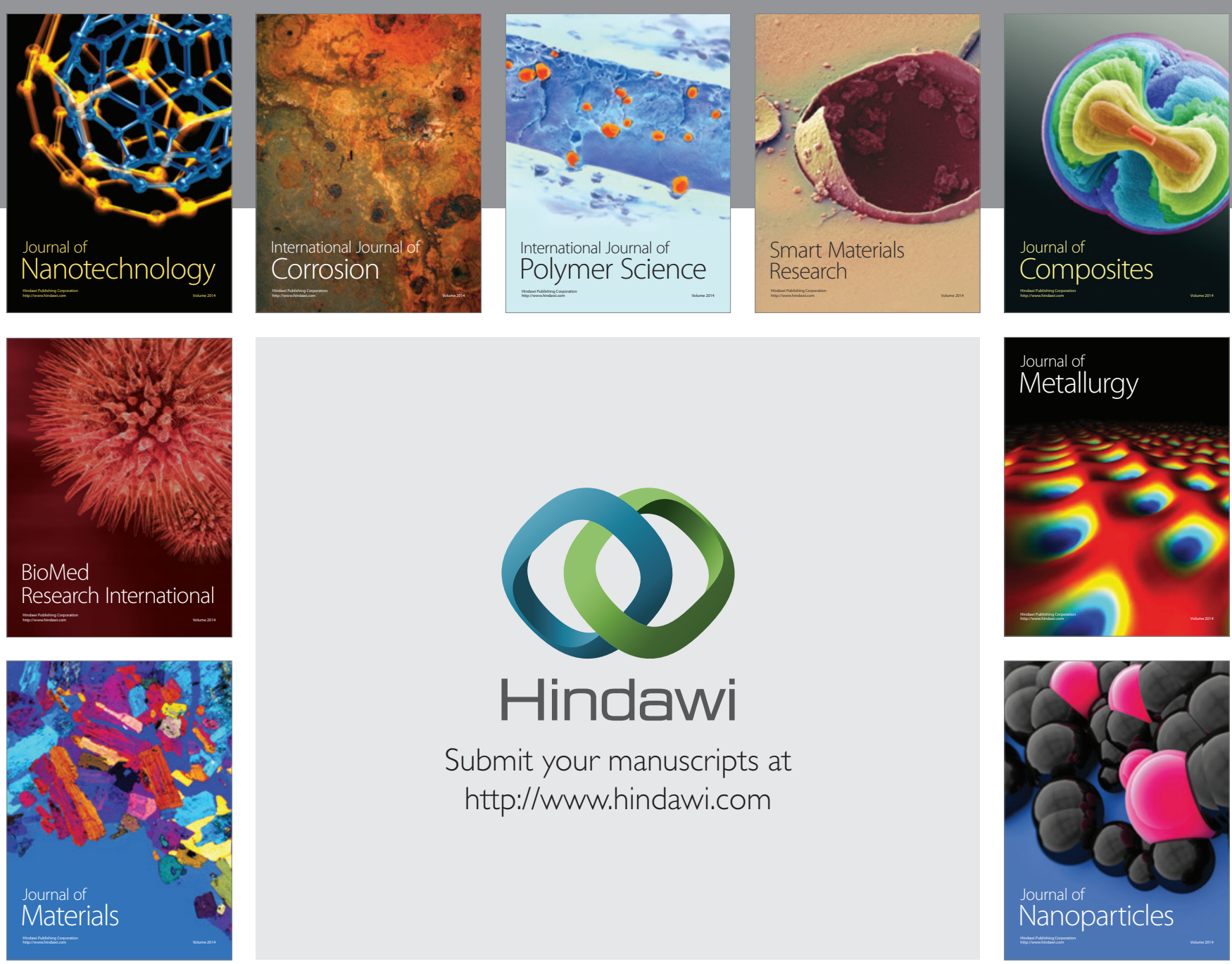

Submit your manuscripts at http://www.hindawi.com


\section{The Scientific World Journal}
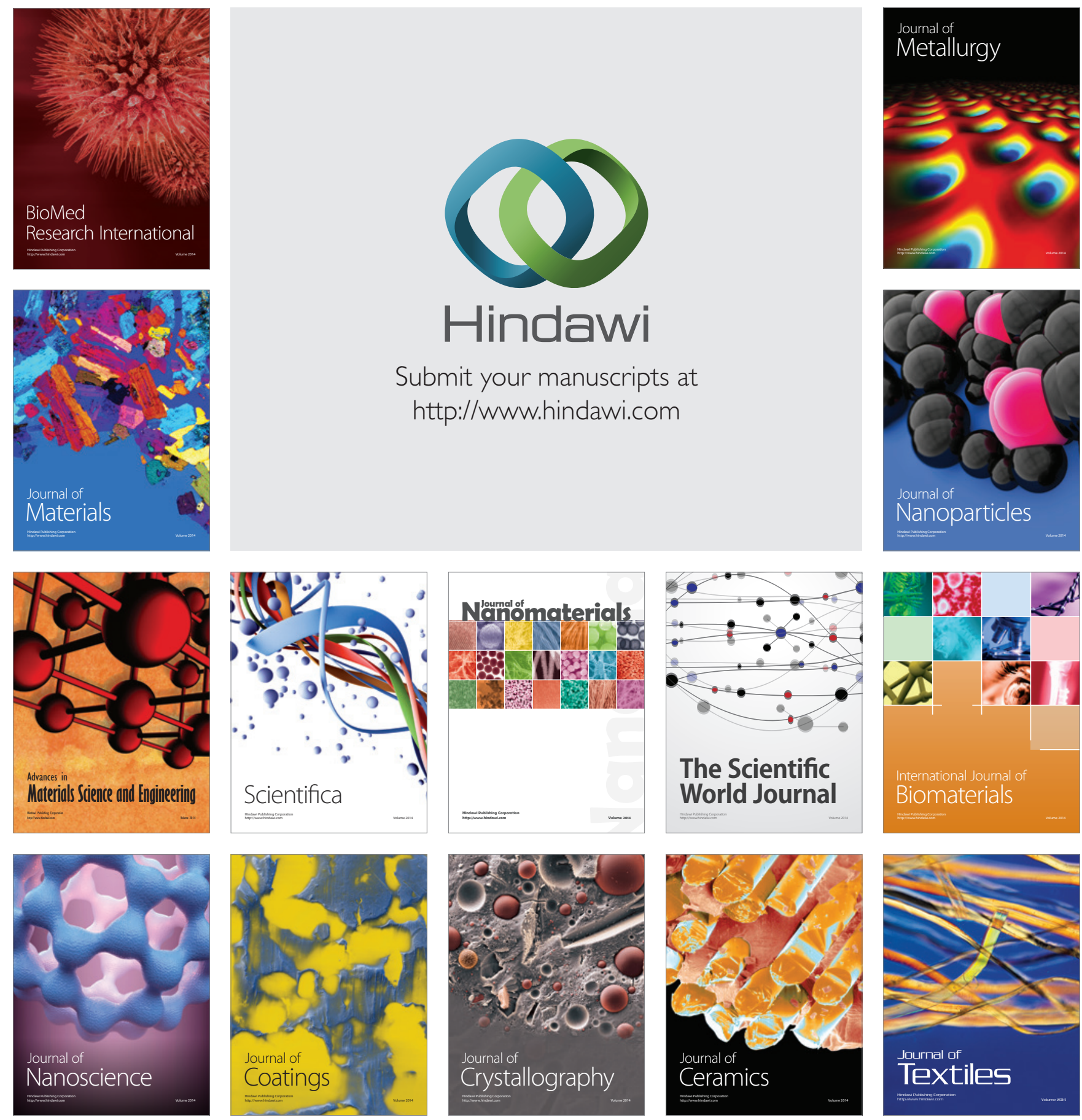